Research Article

\title{
Effects of Laser Scanning Speed on Microstructure, Microhardness, and Corrosion Behavior of Laser Cladding Ni45 Coatings
}

\author{
Yanxin Qiao $\mathbb{D}^{1}{ }^{1}$ Jie Huang, ${ }^{1}$ Ding Huang, ${ }^{1}$ Jian Chen, ${ }^{1}$ Wen Liu, ${ }^{1}$ Zhengbin Wang $\mathbb{D},{ }^{2}$ \\ and Zheng Zhibin ${ }^{3}$ \\ ${ }^{1}$ School of Materials Science and Engineering, Jiangsu University of Science and Technology, Zhenjiang 212003, China \\ ${ }^{2}$ CAS Key Laboratory of Nuclear Materials and Safety Assessment, Institute of Metal Research, Chinese Academy of Sciences, \\ Shenyang 110016, China \\ ${ }^{3}$ Guangdong Key Laboratory for Technology and Application of Metal Toughening, \\ Guangdong Institute of Materials and Processing, Guangzhou 510650, China
}

Correspondence should be addressed to Yanxin Qiao; yxqiao@just.edu.cn and Zhengbin Wang; zbwang12s@imr.ac.cn

Received 30 January 2020; Revised 15 June 2020; Accepted 9 July 2020; Published 3 August 2020

Academic Editor: Mohamed Azaroual

Copyright (C) 2020 Yanxin Qiao et al. This is an open access article distributed under the Creative Commons Attribution License, which permits unrestricted use, distribution, and reproduction in any medium, provided the original work is properly cited.

\begin{abstract}
The effects of laser scanning speed on the microstructure, microhardness, and corrosion behavior of Ni45 coatings were investigated by using optical microscopy (OM), scanning electron microscopy (SEM), X-ray diffraction (XRD), microhardness, and electrochemical measurements. The results showed that increasing laser scanning speed promotes the transformation from planar crystals to dendrites and refines the grains concurrently. The $\gamma$ - $(\mathrm{Ni}, \mathrm{Fe}), \mathrm{FeNi}_{3}$, and $\mathrm{M}_{23}(\mathrm{C}, \mathrm{B})_{6}$ are identified as the primary phase composition in the Ni45 coatings regardless of the laser scanning speed. Thereinto, the formation and growth of $\mathrm{M}_{23}(\mathrm{C}, \mathrm{B})_{6}$ precipitates can be inhibited with increasing laser scanning speed due to the higher cooling rate, which affects the microhardness distribution and corrosion resistance of the coating. On the one hand, the microhardness of the whole coating presents a downtrend with increasing laser scanning speed due to the reduction of $\mathrm{M}_{23}(\mathrm{C}, \mathrm{B})_{6}$ phase. On the other hand, the corrosion resistance in $0.5 \mathrm{M} \mathrm{NaCl}$ solution is improved to some extent at higher laser scanning speed because the less precipitation of $\mathrm{M}_{23}(\mathrm{C}, \mathrm{B})_{6}$ reduces the depletion of $\mathrm{Cr}$ around the precipitates. In contrast, all the coatings exhibit undifferentiated but poor corrosion resistance in the highly corrosive $0.5 \mathrm{M} \mathrm{NaCl}+0.5 \mathrm{M} \mathrm{H}_{2} \mathrm{SO}_{4}$ solution.
\end{abstract}

\section{Introduction}

Cladding technologies are usually employed to modify the surface structure and properties of alloys [1,2], among which laser cladding exhibits some promising advantages [3-5]. First, it is a simple, green, economic, and efficient process, which can make the surface coating have better corrosion resistance and wear resistance than the substrate $[6,7]$. Secondly, a strong metallurgical bond can form between the coating and substrate $[4,8,9]$, and the size of the heat-affected zone (HAZ) is usually small $[4,10,11]$. Lastly, it is relatively easy to control the process parameters and to be automated $[4,12,13]$. Liu et al. [5] developed a composite coating by laser cladding on Ti-6Al-4V alloy with superior wear resistance. The results showed that the average microhardness and wear loss of the coating were twice larger and 10 30\% lower than those of the substrate, respectively. Fesharaki et al. [14] reported better metallurgical bonding of Inconel 625 coating prepared by laser cladding than that developed by Tungsten Inert Gas Welding (TIG) cladding. Tanigawa et al. [15] found that the HAZ of laser cladding prepared Ni-Cr-Si-B alloy coating on $\mathrm{C} 45$ carbon steel can be shrunken by employing smaller particles.

Nickel-based superalloys are widely used in the laser cladding process due to their superior mechanical properties and wear resistance [16-18]. Chen et al. [3] found that the 
microhardness of the Ni-Cr-B-Si composite coatings increased with increasing laser scanning speed $(5,10,15$, and $20 \mathrm{~mm} / \mathrm{s}$ ). Sun et al. [19] studied the effects of $\mathrm{NbC}$ on the wear properties of Ni45 coating and reported that the microhardness and wear resistance were significantly improved by the addition of $\mathrm{NbC}$. However, these works are mainly focused on the hardness and wear resistance with very little attention on corrosion behavior. Keeping in mind that corrosion is usually one of the reasons for the reduction in the service life of nickel-based alloys, it is, therefore, worthwhile to evaluate the corrosion resistance of nickelbased alloy coatings prepared by laser cladding, especially to clarify the correlation between corrosion resistance and microstructure.

For this purpose, three laser cladded nickel-based alloy coatings on carbon steel substrate were prepared, adjusting the microstructure by controlling the laser scanning speed $(4 \mathrm{~mm} / \mathrm{s}, 6 \mathrm{~mm} / \mathrm{s}$, and $10 \mathrm{~mm} / \mathrm{s})$. The effects of laser scanning speed on the microstructure, microhardness, and corrosion behavior were investigated by optical microscopy (OM), scanning electron microscopy (SEM), X-ray diffraction (XRD), microhardness, and electrochemical measurements. The evolution of microhardness and corrosion behavior with laser scanning speed was explained in terms of microstructure.

\section{Experimental Methods}

2.1. Preparation of Ni45 Coatings. The substrate material used in this study was medium carbon steel AISI 1045 (0.42 0.50 wt.\% C, 0.17 0.37 wt.\% Si, 0.50 0.80 wt.\% Mn, 0.25 wt. $\% \mathrm{Cr}, \leq 0.25$ wt. $\% \mathrm{Cr}, \leq 0.30$ wt. $\% \mathrm{Ni}, \leq 0.25$ wt. $\% \mathrm{Cu}$, $\leq 0.035$ wt.\% $\mathrm{P}$ and $\mathrm{Fe}$ balance) with dimensions $110 \mathrm{~mm} \times 100 \mathrm{~mm} \times 10 \mathrm{~mm}$. The surface of the substrate was ground with 150\# sandpaper and cleaned with acetone. Ni45 powder (0.34 wt.\% C, 2.0 wt.\% B, 4.1 wt.\% Si, 12.5 wt.\% Cr, 6.6 wt.\% Fe and Ni balance) obtained from Beijing AMC Powder Metallurgy Technology Co., Ltd. (Beijing, China), was employed as the cladding material, and its SEM morphology is shown in Figure 1. Before laser cladding, the alloy powder was baked in a vacuum environment (to remove moisture and avoid oxidation) and then ground in a mortar for at least 5 minutes to guarantee uniformity in powder mixing.

$\mathrm{CO}_{2}$ laser with Siemens $820 \mathrm{C}$ computer numerical control $(\mathrm{CNC})$ system was used in preparing the coating. The schematic of the laser cladding process employed in this work is shown in Figure 2, and the operating parameters are listed in Table 1. Before the experiment, the cladding powder and bonder were preplaced on the surface of AISI 1045 steel by a self-made powder paving device. After the laser cladding, the samples were cut into coupons with dimensions $10 \mathrm{~mm} \times 10 \mathrm{~mm} \times 5 \mathrm{~mm}$. Then, the samples were cleaned and inlaid for subsequent microstructure observation and property testing.

2.2. Microstructure Observation and Microhardness Measurement. The crystal structures of the Ni45 coatings were investigated by an X-ray diffractometer (XRD, Bruker

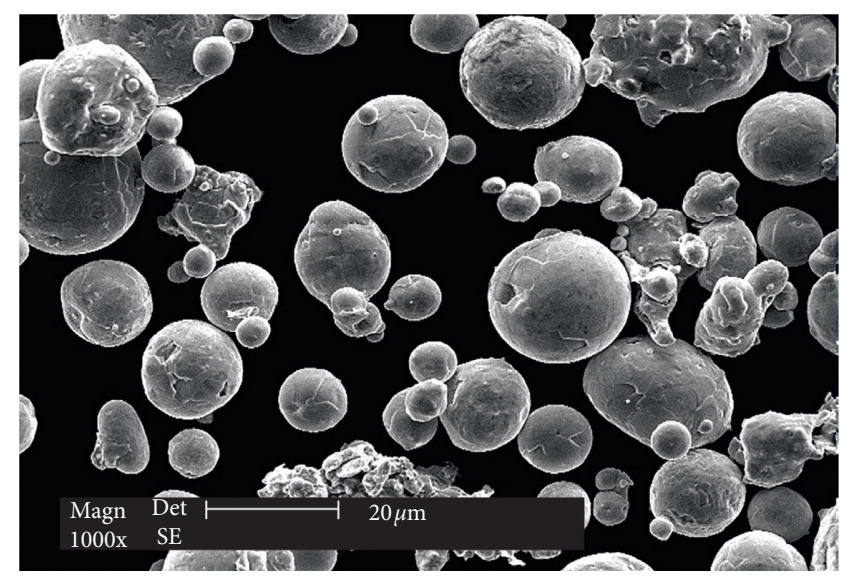

Figure 1: SEM morphology of Ni45 powders.

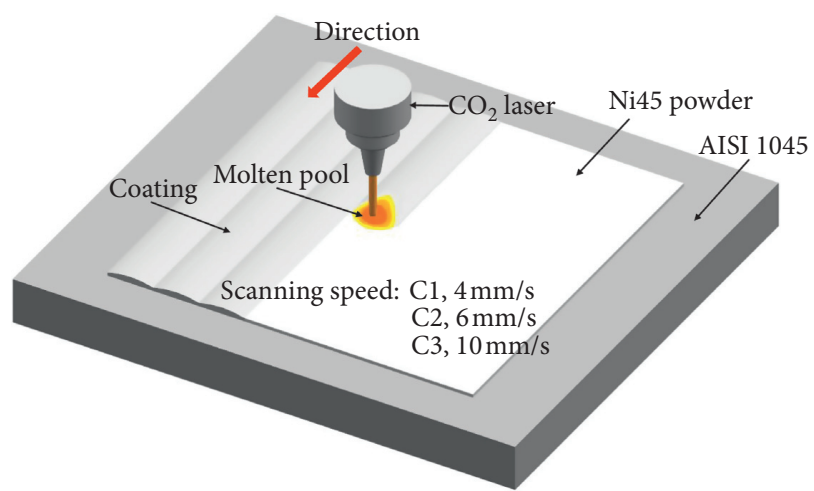

Figure 2: Schematic of the laser cladding process.

TABLE 1: Operating parameters of the laser cladding process.

\begin{tabular}{lc}
\hline Operating parameters & Values \\
\hline Output power $(W)$ & 1600 \\
Scanning speed $(\mathrm{mm} / \mathrm{s})$ & $4(\mathrm{C} 1), 6(\mathrm{C} 2), 10(\mathrm{C} 3)$ \\
Beam diameter $(\mathrm{mm})$ & 4 \\
Overlapped width $(\mathrm{mm})$ & 2.5 \\
The number of passes & 8 \\
Protective gas rate $(\mathrm{L} / \mathrm{min})$ & 10 \\
Carrier gas flow rate $(\mathrm{L} / \mathrm{min})$ & 12 \\
\hline
\end{tabular}

D8 Advance) with the diffraction angle (2 $\theta)$ ranging from $10^{\circ}$ to $90^{\circ}$ and a Cu-Ka radiation at $40 \mathrm{kV}$ and $35 \mathrm{~mA}$ at a step size of $0.02^{\circ}$ and a scan rate of $6 \% \mathrm{~min}$. The microstructures of the as-prepared coatings were characterized by an optical microscope (OM, KEYENCE-VHX-900E) and scanning electron microscope (SEM, XL30-FEG ESEM) with energy dispersive spectroscope (EDS, Oxford INCA) after the samples were mechanically polished and etched in the 3 wt.\% $\mathrm{HNO}_{3}$ solution. The microhardness distribution along the cross section of the Ni45 coatings was measured using HDX-1000 microhardness tester with a load of $300 \mathrm{~g}$ and a dwell time of $15 \mathrm{~s}$. 
2.3. Electrochemical Corrosion Test. The electrochemical corrosion behavior of the as-prepared coatings was assessed using CS350 electrochemical workstation (Wuhan Corrtest Instruments Corp., Ltd., Wuhan, China) in $0.5 \mathrm{M} \mathrm{NaCl}$ solution and $0.5 \mathrm{M} \mathrm{NaCl}+0.05 \mathrm{M} \mathrm{H}_{2} \mathrm{SO}_{4}$ solution. All the electrochemical tests were conducted using a three-electrode electrochemical cell composed of a saturated calomel reference electrode (SCE), a platinum counter electrode, and a coated sample working electrode [20]. Preceding the electrochemical tests was the monitoring of the open circuit potential (OCP) for $1 \mathrm{~h}$ to achieve a relatively stable state. The electrochemical impedance spectroscopy (EIS) tests were performed at OCP with a sinusoidal potential perturbation of $10 \mathrm{mV}$ in a frequency range from $10^{5} \mathrm{~Hz}$ to $10^{-2} \mathrm{~Hz}$. The potentiodynamic polarization curves were measured by sweeping the potential from $-0.6 \mathrm{~V}_{\mathrm{SCE}}$ to 2.0 $\mathrm{V}_{\mathrm{SCE}}$ at a scanning rate of $0.5 \mathrm{mV} / \mathrm{s}$ and terminated when the current density of $50 \mathrm{~mA} / \mathrm{cm}^{2}$ was reached. The electrochemical tests were conducted at $25 \pm 1^{\circ} \mathrm{C}$ in the air without stirring, and triplicate measurements were done to ensure repeatability.

\section{Results and Discussion}

3.1. Morphology Observation. Figure 3 shows the surface appearance of Ni45 coatings after laser cladding processes. The coating material was melted sufficiently, and continuous coatings were formed on the substrate. All coatings had a uniform geometric appearance, and the overlaps between adjacent passes were almost parallel to each other.

Figure 4 displays the $\mathrm{OM}$ of the transition layers between the coatings and substrate. All the interfaces were free of cracks and pores, indicating good bondings between the substrate and coatings. The thickness of the transition layer between the coating and HAZ decreased with increasing laser scanning speed, which resulted from the hindered element diffusion between the coatings and substrate at a shorter heating time during the laser cladding process $[8,21,22]$. Many columnar grains appeared around the transition layer, due to extreme undercooling at the bottom of the molten pool [23]. Meanwhile, the direction of columnar growth was basically perpendicular to the transition layer along the direction opposite to the thermal flow movement $[8,13,23,24]$. These features of columnar grains and microstructures are basically independent of the laser scanning speed. The cross-section microstructures of the asprepared Ni45 coatings were observed by SEM in backscattered electron mode and are presented in Figure 5. As seen in Figures 5(d)-5(f), more and finer dendrites appeared as the laser scanning speed increased from $4 \mathrm{~mm} / \mathrm{s}$ to $10 \mathrm{~mm} / \mathrm{s}$, demonstrating that the grains tend to grow into finer dendrites at higher laser scanning speed. Also, many precipitation phases were observed in the intergranular areas for all the coatings [25].

According to the solidification theory, the alloy solidification mode mainly includes planar, cellular, dendritic, and equiaxed growth, which depends on the ratio of the temperature gradient $(\mathrm{G})$ to solidification rate $(\mathrm{R})$, i.e., $\mathrm{G} / \mathrm{R}$ $[13,21,24,26,27]$. The temperature gradient was the largest

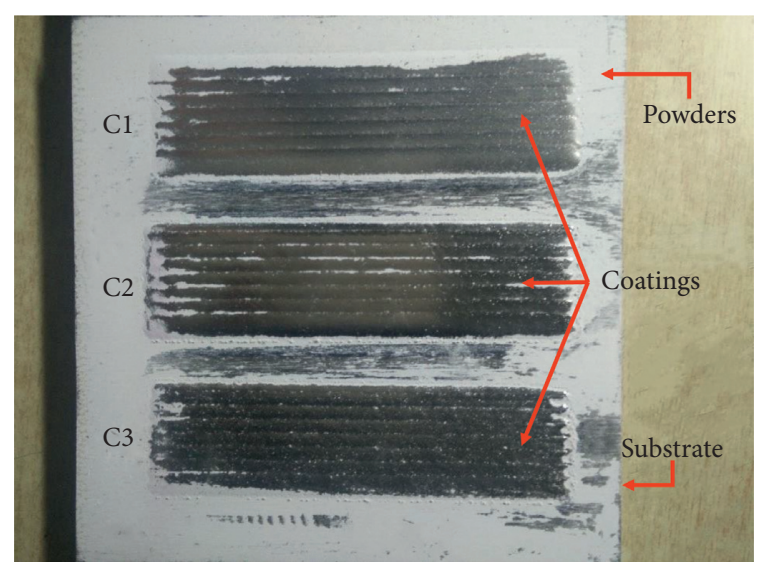

Figure 3: Surface appearance of Ni45 coatings after laser cladding processes.

at the beginning of the solidification process due to the low temperature of the substrate and the fact that the solidification rate was close to zero. Under this condition, the solidliquid interface is stable, and a layer of planar front growth can form between coatings and substrates, just like the transition layer shown in Figure $3[13,21,26,27]$. With the increase in distance from the bottom of the molten pool, the temperature gradient will decrease [26], and the solidification speed will increase $[8,24]$, resulting in a dramatic decline of $G / R$. As a result, the solid-liquid interface of the planar grain becomes unstable, promoting the transition of microstructure from plane crystals to cellular crystals $[8,21,26]$. With further movement of the solid-liquid interface far away from the bottom of the molten pool, the value of $G / R$ becomes much smaller, resulting in the change of crystal growth mode from cellular to dendritic growth $[26,27]$, as shown in Figure 5. At the top of the molten pool, the dendrites transformed into equiaxed crystals due to the further decline of $G / R$ caused by the heat released to the surrounding environment from multiple directions $[21,26,27]$. Accordingly, increasing the laser scanning speed will affect the microstructure evolution during the solidification process from two aspects. On the one hand, the value of $G / R$ will decrease, which accelerates the transformation from planar crystals to cellular crystals and dendrites consequently $[26,28]$. On the other hand, the grains nucleate abundantly due to the lower heat input and the more rapid solidification, resulting in the refinement of grains $[13,21,22,26,29]$. As a result, more and finer dendrites can be observed in the coatings prepared at higher laser scanning speed, as shown in Figure 5.

3.2. XRD and EDS Measurements. Figure 6 exhibits the XRD patterns of the as-prepared Ni45 coatings. The characteristic peaks correspond to the $\gamma-(\mathrm{Ni}, \mathrm{Fe}), \mathrm{FeNi}_{3}$, and $\mathrm{M}_{23}(\mathrm{C}, \mathrm{B})_{6}$, respectively. Thereinto, the intensity of $\mathrm{M}_{23}(\mathrm{C}, \mathrm{B})_{6}$ peak showed the most noticeable difference among the three kinds of coatings, which decreased with the increase in laser scanning speed and even disappeared at $10 \mathrm{~mm} / \mathrm{s}$. Kesavan et al. [30] studied the microstructure characterization of a 


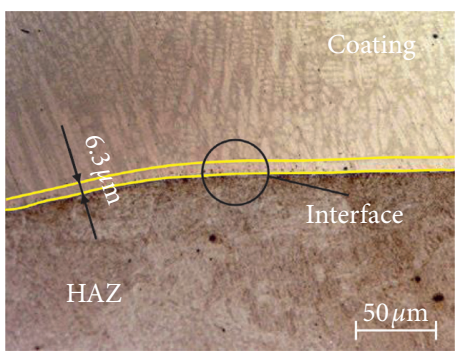

(a)

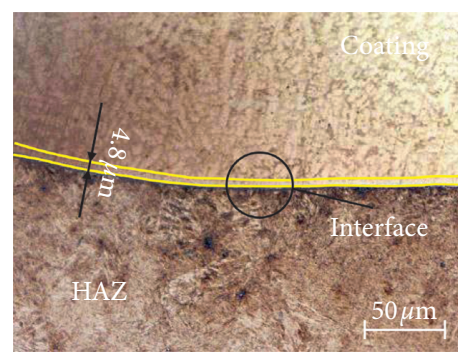

(b)

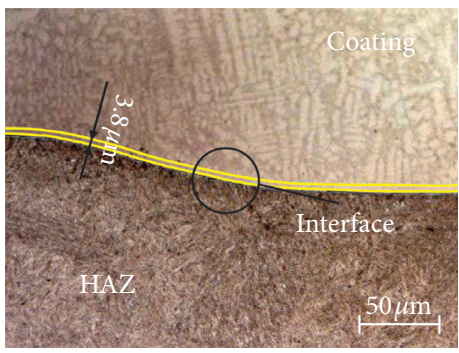

(c)

Figure 4: Optical microstructure of the interface between the substrate and the Ni45 coatings: (a) C1, (b) C2, and (c) C3.

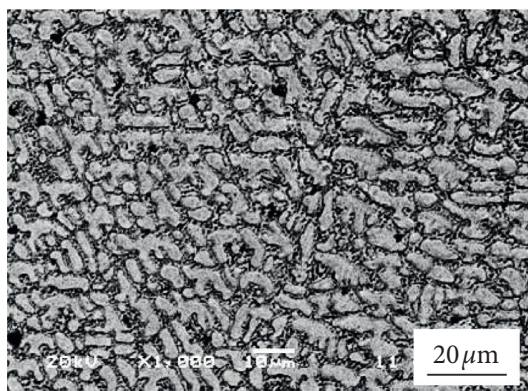

(a)

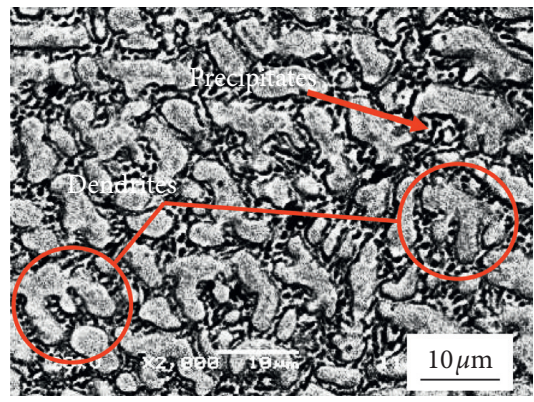

(d)

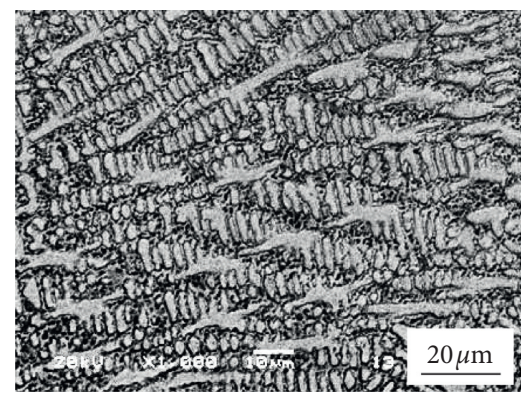

(b)

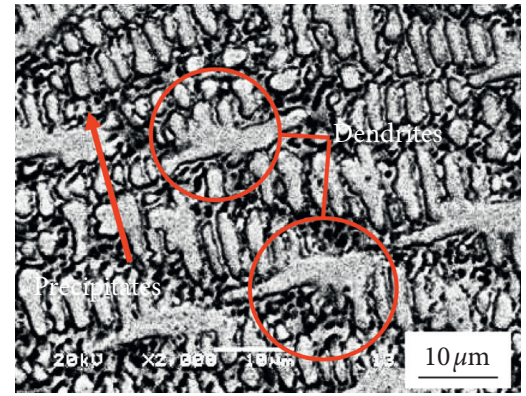

(e)

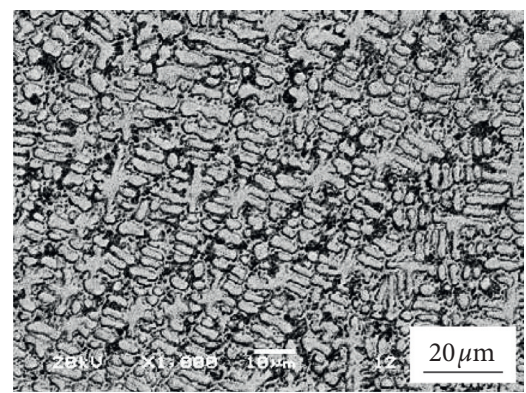

(c)

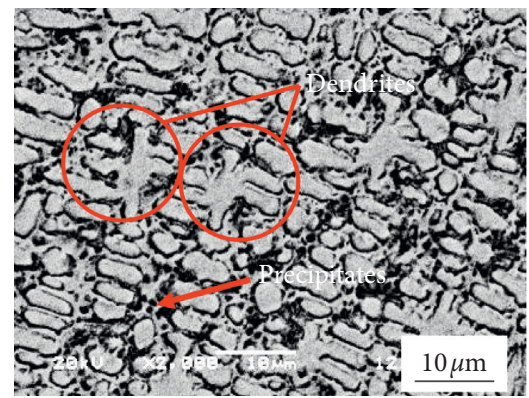

(f)

FIgURE 5: SEM images in backscattered electron mode of the cross-section microstructures of (a, d) C1, (b, e) C2, and (c, f) C3 coatings.

nickel-base hard-faced coating and reported that the microstructure of the deposits can be divided into dendrite and interdendritic regions. The dendrite region was composed of the $\gamma$-nickel phase, while the interdendritic region was composed of $\mathrm{Cr}$-rich carbide and boride precipitates that are needle-, blocky-, floret-, and fine spherical-shaped. Liu et al. [31] investigated the microstructure of NiCoCrAlY coating deposited on cast iron using multilayer laser cladding. They described the dendrite in NiCoCrAlY alloy coating as the $\gamma$ - $(\mathrm{Fe}, \mathrm{Ni})$ solid solution, and the phases in the interdendritic region as $\mathrm{M}_{7} \mathrm{C}_{3}$ and $\mathrm{M}_{23} \mathrm{C}_{6}$ carbides, where $\mathrm{M}$ represents $\mathrm{Cr}$, $\mathrm{Fe}$, or $\mathrm{Ni}$.

It can be inferred that the dendrite region was composed of $\gamma$-phase, whereas the black particle phases in the interdendritic region were $\mathrm{M}_{23}(\mathrm{C}, \mathrm{B})_{6}$ precipitations. Meanwhile, the intensity of $\mathrm{M}_{23}(\mathrm{C}, \mathrm{B})_{6}$ peak was not noticeably observed in the XRD pattern of C2 and C3 coatings, which reflects that the volume fraction of
$\mathrm{M}_{23}(\mathrm{C}, \mathrm{B})_{6}$ precipitations decreased with increasing laser scanning speed [32]. This can be attributed to the high cooling rate induced by the high laser scanning speed $[3,28]$. The inhibition of $\mathrm{M}_{23}(\mathrm{C}, \mathrm{B})_{6}$, together with the refined grain (Figure 5), could have effects on the microhardness and corrosion resistance of the Ni45 coatings $[13,30]$, which will be discussed in the following sections.

The elemental content of the dendrites in the $\mathrm{C} 3$ coating measured by EDS is listed in Figure 7. Only the contents of $\mathrm{Fe}, \mathrm{Cr}, \mathrm{Ni}$, and $\mathrm{Si}$ were detected in the $\mathrm{C} 3$ coating because of the poor sensitivity of EDS in detecting light elements $[13,33]$. Compared with the original Ni45 powders, the content of element $\mathrm{Si}, \mathrm{Cr}$, and $\mathrm{Ni}$ changed less after the laser cladding process, but a remarkable increase in the Fe content was observed. It indicates the element diffusion occurring between the substrate and the coating during the laser cladding process [34] and, therefore, demonstrating the formation of the transition layer discussed in Section 3.1. 


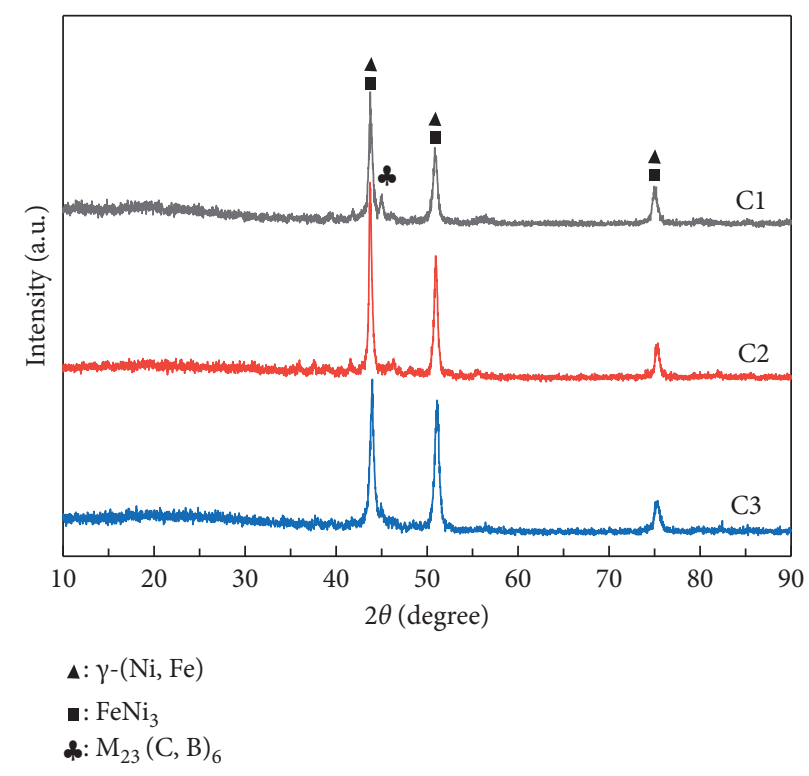

FIGURE 6: XRD patterns of as-prepared Ni45 coatings.

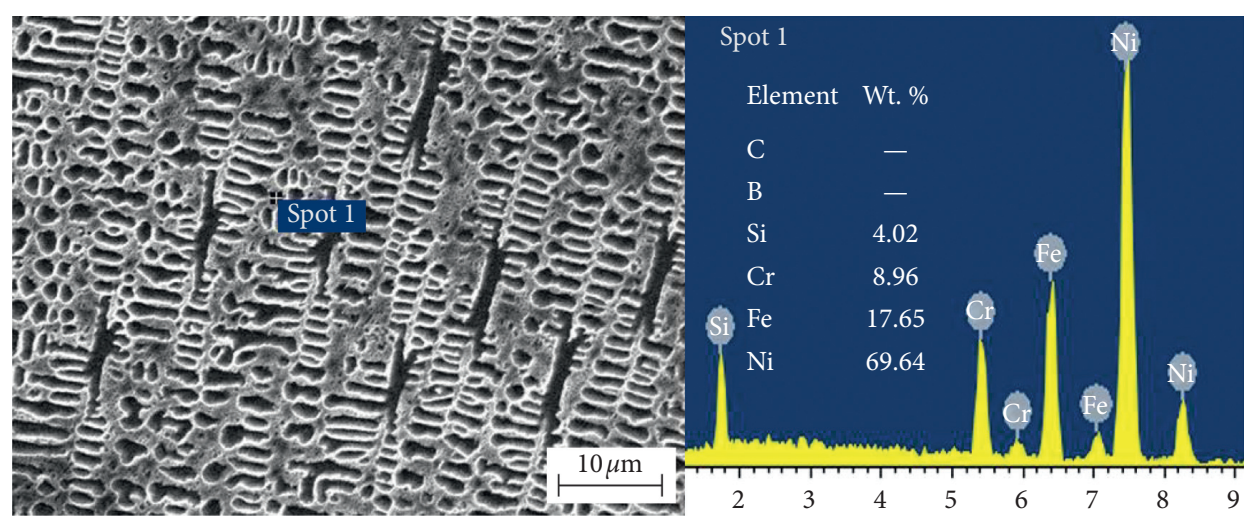

FIgURe 7: EDS analyses of the dendrites in C3 coating.

3.3. Microhardness Measurements. Figure 8 shows the microhardness distribution along the cross section of the as-prepared Ni45 coatings, in which the height and width of the rectangle represent the microhardness and the depth of different regions, respectively. The microhardness of the $\mathrm{Ni} 45$ coating ranges from $313.8 \mathrm{HV}$ to $556.8 \mathrm{HV}$, which is significantly higher than that of the substrate. With increasing laser scanning speed, the microhardness of the coating decreased, while that of the substrate remained relatively unchanged. On the one hand, the higher laser scanning speed inhibited the formation and growth of borides and carbides, i.e., $\mathrm{M}_{23}(\mathrm{C}, \mathrm{B})_{6}$ in Figure 6, which weakened the effect of precipitation strengthening $[12,13]$. On the other hand, the grains were refined due to the higher cooling speed (Figure 5), leading to the improvement of microhardness $[3,13,22]$. Based on these two aspects, precipitation strengthening should be the dominant factor determining the microhardness of $\mathrm{Ni} 45$ coatings studied in this work [13]. Besides, the as-prepared coatings can be further divided into two parts based on the obvious step change of coatings microhardness: the top and the bottom coatings. The microhardness of the top coatings was lower than that of the bottom when the laser scanning speed was $4 \mathrm{~mm} / \mathrm{s}$, while the relationship reversed at $6 \mathrm{~mm} / \mathrm{s}$ and $10 \mathrm{~mm} / \mathrm{s}$. During the solidification process, the solidification phase transition occurred first at the bottom and then advanced to the top [28]. With continuous heating from the postsolidified metal droplets, the bottom microstructure grew coarsely [21, 23], whereas the top microstructure solidified rapidly and had no time to grow more coarsely due to the cooling effects of the external environments $[21,26]$. Meanwhile, at low laser scanning speed $(4 \mathrm{~mm} / \mathrm{s})$, there was enough time for the growth of carbides and borides, especially at the bottom, resulting in a higher microhardness of bottom coatings $[3,28]$. The precipitation strengthening, in other words, should be the key factor determining the microhardness distribution inside the coating region at low scanning speed $(4 \mathrm{~mm} / \mathrm{s})$. The higher the laser scanning speed, the fewer the amount of the precipitate of carbides and borides. As a result, the main 


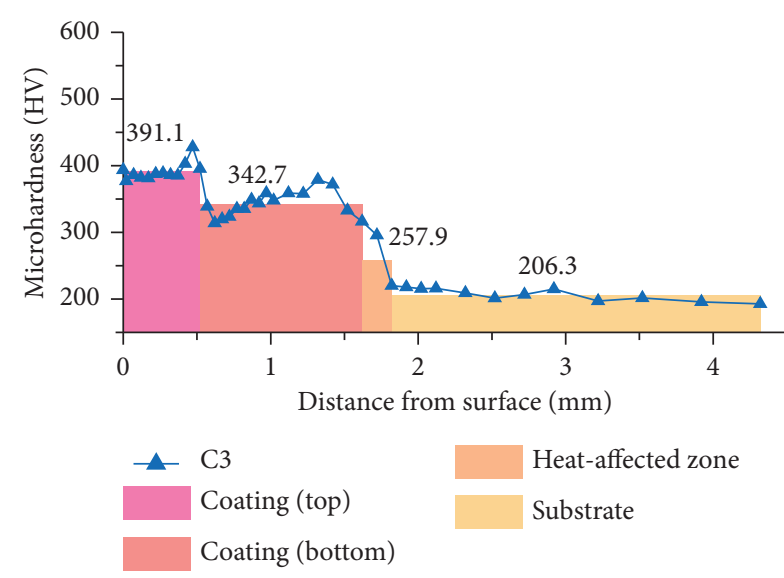

(a)

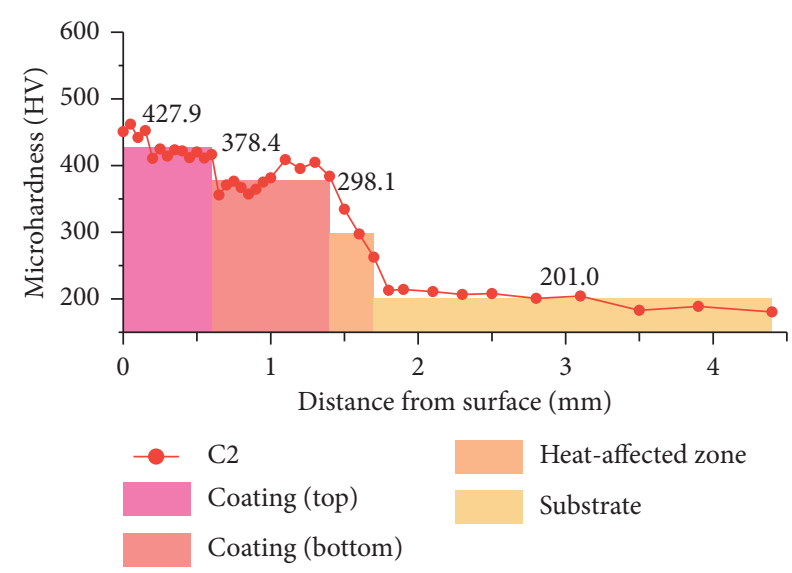

(b)

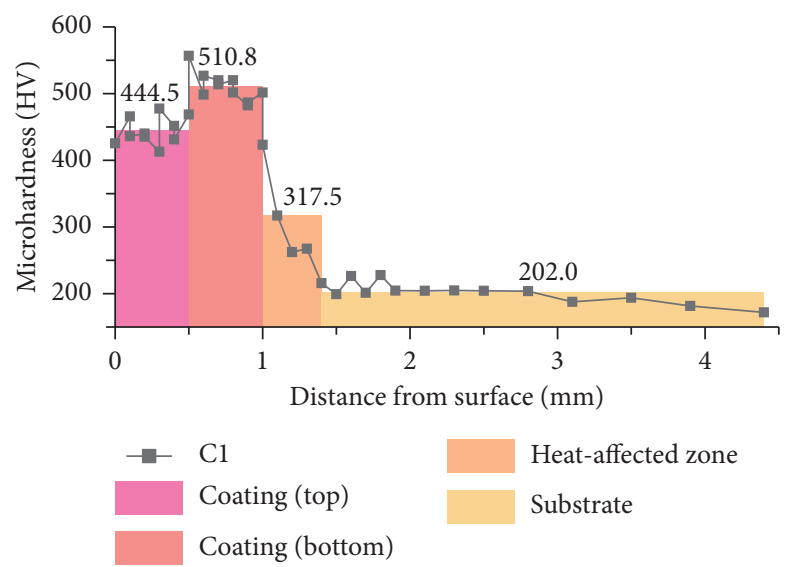

(c)

Figure 8: Microhardness distribution along the cross section of the as-prepared Ni45 coatings. The height and width of the colored rectangles represent the microhardness and the depth of different regions in the coatings.

strengthening mechanism influencing microhardness distribution could change from precipitation strengthening to grain refinement strengthening, leading to a higher microhardness of top coatings at high scanning speeds $(6 \mathrm{~mm} / \mathrm{s}$ and $10 \mathrm{~mm} / \mathrm{s})$.

In conclusion, whether the strengthening mechanism is precipitation strengthening or grain refinement strengthening, the coating microhardness can be improved effectively. For the whole coatings, the precipitation strengthening made more contribution to enhancing the microhardness of the coatings compared with the grain refinement strengthening. For hardness distribution inside the coating region, the controlling strengthening mechanism depended on the laser scanning speed. When the laser scanning speed was as low as $4 \mathrm{~mm} / \mathrm{s}$, the microhardness distribution was mainly influenced by the precipitation strengthening, whereas the grain refinement strengthening was the key factor determining the microhardness distribution as the laser scanning speed was increased to $6 \mathrm{~mm} / \mathrm{s}$ and $10 \mathrm{~mm} / \mathrm{s}$.

3.4. Electrochemical Corrosion Behavior. The potentiodynamic polarization curves of the Ni45 coatings in $0.5 \mathrm{M}$ $\mathrm{NaCl}$ and $0.5 \mathrm{M} \mathrm{NaCl}+0.5 \mathrm{M} \mathrm{H}_{2} \mathrm{SO}_{4}$ solution are displayed in Figure 9. The values of corrosion current density $\left(i_{\text {corr }}\right)$ and corrosion potential $\left(E_{\text {corr }}\right)$ based on Tafel extrapolation analysis are listed in Table 2 . In both two solutions, the anodic current densities of all the coatings increased with the applied potential without exhibiting any active-to-passive transition. In $0.5 \mathrm{M} \mathrm{NaCl}$ solution, the corrosion potentials shifted nobly while the corrosion current densities decreased with the increase in laser scanning speed. It proves that the corrosion resistance of coatings in $0.5 \mathrm{M} \mathrm{NaCl}$ solution is improved by increasing the laser scanning speed $[20,28,34,35]$. In contrast, lower corrosion potentials and higher corrosion current densities were observed for all coatings in $0.5 \mathrm{M} \mathrm{NaCl}+0.5 \mathrm{M} \mathrm{H}_{2} \mathrm{SO}_{4}$ solution, implying a poor corrosion resistance in the more acidic environment. Moreover, the laser scanning speed seems to have no obvious effects on the corrosion resistance of $\mathrm{Ni} 45$ coatings in $0.5 \mathrm{M} \mathrm{NaCl}+0.5 \mathrm{M} \mathrm{H}_{2} \mathrm{SO}_{4}$ solution, as shown in Figure 9(b) and Table 2.

Figure 10 depicts the Nyquist plots of the as-prepared $\mathrm{Ni} 45$ coatings in $0.5 \mathrm{M} \mathrm{NaCl}$ and $0.5 \mathrm{M} \mathrm{NaCl}+0.5 \mathrm{M} \mathrm{H}_{2} \mathrm{SO}_{4}$ solutions. In $0.5 \mathrm{M} \mathrm{NaCl}$ solution (Figure $10(\mathrm{a})$ ), one apparent unfinished capacitive impedance arc can be identified for all coatings. The radius of the capacitive impedance arc increased with the laser scanning speed, indicating the 


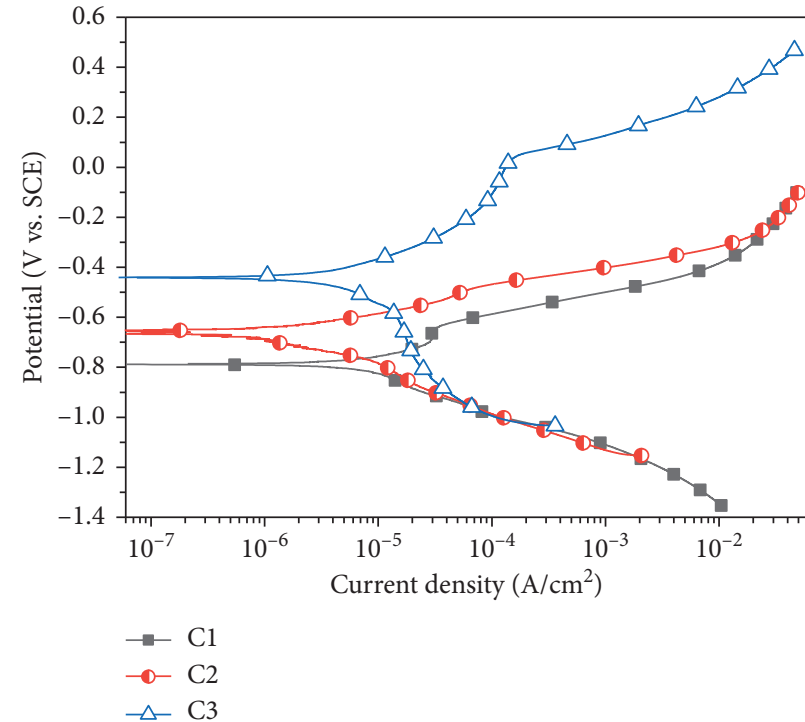

(a)

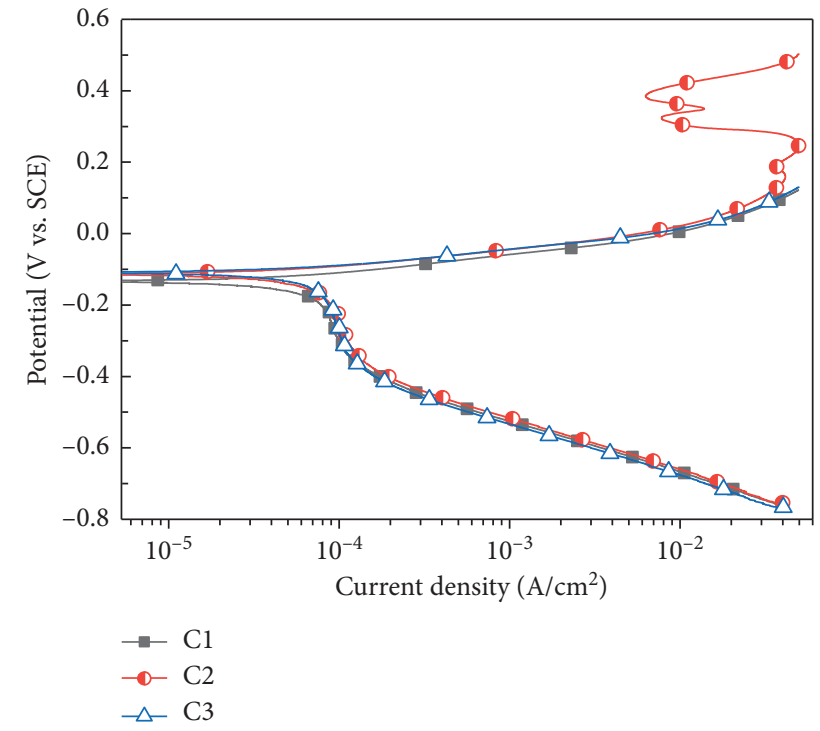

(b)

Figure 9: Potentiodynamic polarization curves of as-prepared Ni45 coatings in (a) $0.5 \mathrm{M} \mathrm{NaCl}$ and (b) $0.5 \mathrm{M} \mathrm{NaCl}+0.5 \mathrm{M} \mathrm{H}_{2} \mathrm{SO}_{4}$ solutions.

TABLE 2: Corrosion current density $\left(i_{\text {corr }}\right)$ and corrosion potential $\left(E_{\text {corr }}\right)$ of as-prepared $\mathrm{Ni} 45$ coatings in $0.5 \mathrm{M} \mathrm{NaCl}$ and $0.5 \mathrm{M}$ $\mathrm{NaCl}+0.5 \mathrm{~mol} / \mathrm{L} \mathrm{H}_{2} \mathrm{SO}_{4}$ solutions.

\begin{tabular}{lcccc}
\hline Coatings & \multicolumn{2}{c}{$0.5 \mathrm{M} \mathrm{NaCl}$} & \multicolumn{2}{c}{$0.5 \mathrm{M} \mathrm{NaCl}+0.5 \mathrm{M} \mathrm{H}_{2} \mathrm{SO}_{4}$} \\
& $\begin{array}{c}E_{\text {corr }} \\
\left(\mathrm{mV}_{\mathrm{SCE}}\right)\end{array}$ & $\begin{array}{c}i_{\text {corr }} \\
\left(\mu \mathrm{A} \cdot \mathrm{cm}^{-2}\right)\end{array}$ & $\begin{array}{c}E_{\text {corr }} \\
\left(\mathrm{mV}_{\mathrm{SCE}}\right)\end{array}$ & $\begin{array}{c}i_{\text {corr }} \\
\left(\mu \mathrm{A} \cdot \mathrm{cm}^{-2}\right)\end{array}$ \\
\hline $\mathrm{C} 1$ & $-786.7 \pm 9.8$ & $8.40 \pm 0.21$ & $-133.6 \pm 2.7$ & $68.01 \pm 1.78$ \\
$\mathrm{C} 2$ & $-666 \pm 8.3$ & $5.62 \pm 0.14$ & $-113.2 \pm 2.4$ & $63.15 \pm 1.58$ \\
$\mathrm{C} 3$ & $-441.2 \pm 5.5$ & $3.74 \pm 0.11$ & $-109.3 \pm 2.3$ & $56.97 \pm 1.46$ \\
\hline
\end{tabular}

improvement in corrosion resistance [26, 28, 36-39]. However, the characteristics of Nyquist plots in $0.5 \mathrm{M}$ $\mathrm{NaCl}+0.5 \mathrm{M} \mathrm{H}_{2} \mathrm{SO}_{4}$ solution (Figure $10(\mathrm{~b})$ ) are different from those in $0.5 \mathrm{M} \mathrm{NaCl}$ solution (Figure 10(a)), which exhibited capacitive impedance arcs with smaller radius but fewer discrepancies among all three coatings, suggesting deteriorated but undifferentiated corrosion resistance. The EIS results are consistent with those of potentiodynamic polarization tests (Figure 9 and Table 2).

The above effects of laser scanning speed on corrosion resistance should be related to the microstructure evolution of Ni45 coatings. It has been reported that the formation of Cr-rich precipitated phases can cause $\mathrm{Cr}$ depletion in the matrix around these precipitates, deteriorating the corrosion resistance in these regions [40-43]. Lei et al. [26] studied the corrosion resistance properties of carbon fiber (CF) reinforced Ni-based composite coating by laser cladding. The results showed that the addition of CFs decreased the amount of $\mathrm{M}_{7} \mathrm{C}_{3}$ and $\mathrm{M}_{23} \mathrm{C}_{6}$ carbides, restraining the formation of $\mathrm{Cr}$-depleted regions at the grain boundaries, thus improving the corrosion resistance of Ni-based alloy composite coatings. Accordingly, the schematic diagrams illustrating the corrosion mechanisms of Ni45 coatings in $0.5 \mathrm{M} \mathrm{NaCl}$ and $0.5 \mathrm{M} \mathrm{NaCl}+0.5 \mathrm{M} \mathrm{H}_{2} \mathrm{SO}_{4}$ solutions are exhibited in Figures 11(a) and 11(b), respectively. In $0.5 \mathrm{M}$
$\mathrm{NaCl}$ solution (Figure 11(a)), the precipitate and coatings acted as the cathodes due to their nobler potential, while the Cr-depleted zone around the precipitates with lower potential acted as the anode $[40,42]$. In this case, the Crdepleted zone dissolved faster than the other zones because of the corrosion microcell, and some precipitates fell off from the matrix. When the laser scanning speed was low, there was relatively sufficient time for the reaction between $\mathrm{Cr}$ and $\mathrm{C}$ element, and more $\mathrm{M}_{23}(\mathrm{C}, \mathrm{B})_{6}$ formed and grew (Figure 6) leading to severer depletion of $\mathrm{Cr}$ around the precipitates. In contrast, less and even no $\mathrm{M}_{23}(\mathrm{C}, \mathrm{B})_{6}$ precipitates formed at higher laser scanning speeds owing to the faster cooling rate (Figure 6). As a result, the Cr-depleted zone and the corresponding corrosion microcell were diminished, which inhibited the corrosion process to some extent. Nonetheless, this inhibition effect of laser scanning speed on corrosion resistance did not exhibit tangible influence in the $0.5 \mathrm{M} \mathrm{NaCl}+0.5 \mathrm{M} \mathrm{H}_{2} \mathrm{SO}_{4}$ solution, as shown in Figure 11(b). It is expected that both the anodic and cathodic reactions will accelerate in strong acidic solutions. In this case, all the regions on the surface, including the matrix, precipitates, and the $\mathrm{Cr}$-depleted zones, dissolved rapidly, implying that the coating surface corroded uniformly layer by layer (Figure 11(b)). As a consequence, the effect of corrosion microcell on the local falloff of precipitates was eliminated. Therefore, the laser scanning speed had less effect on the corrosion resistance of Ni45 coatings.

The mechanism shown in Figure 11(a) can be further verified by the variation trend of $E_{\text {corr }}$ and $i_{\text {corr }}$ with laser scanning speed (Figure 9 and Table 2), which is explained by the means of the mixed potential theory as illustrated in Figure $12[44,45]$. According to the analyses in Figure 11, the effect of laser scanning speed on corrosion resistance was dominated by selective dissolution of Cr-depleted zone, which suggests that the anodic rather than the cathodic 


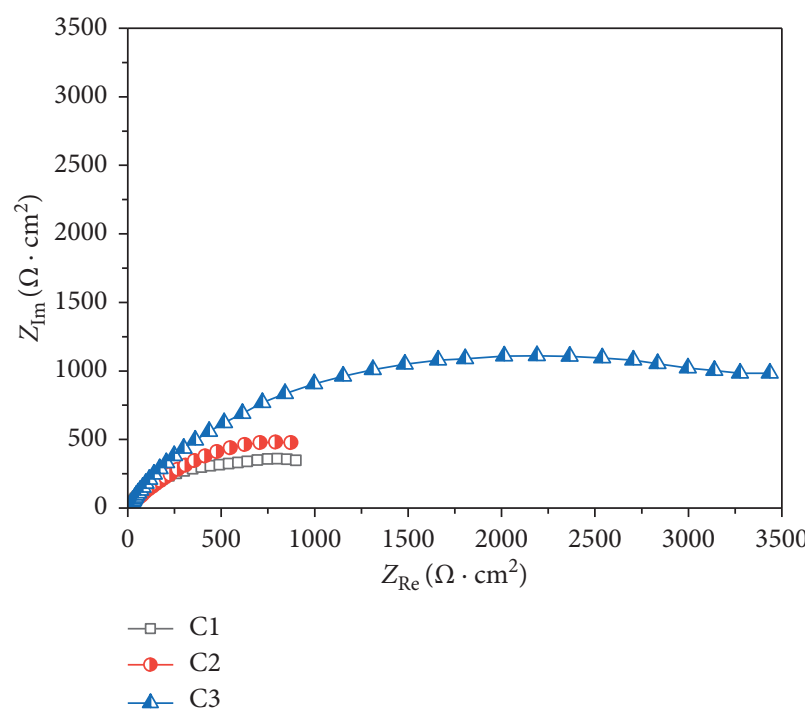

(a)

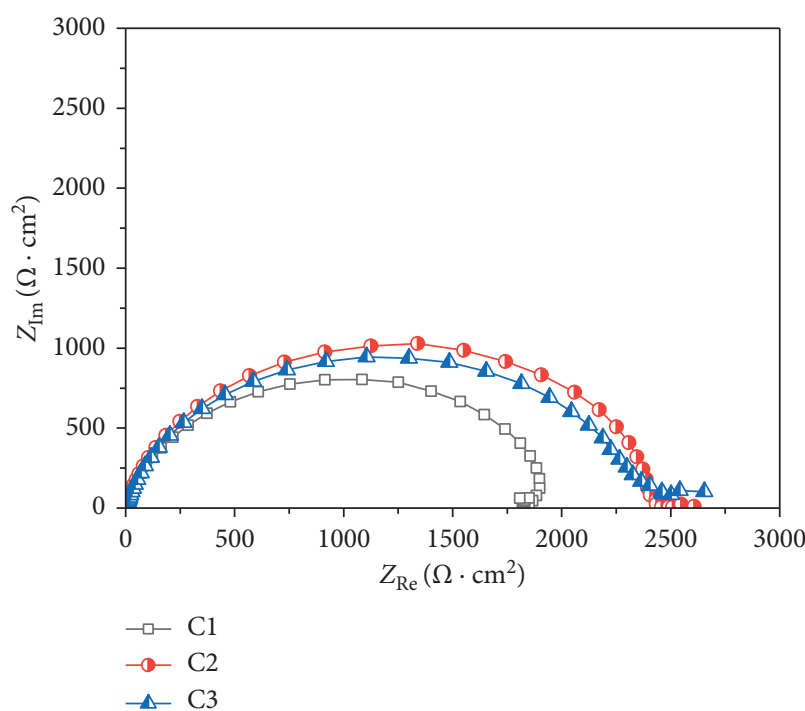

(b)

Figure 10: Nyquist plots of as-prepared Ni45 coatings in (a) $0.5 \mathrm{M} \mathrm{NaCl}$ and (b) $0.5 \mathrm{M} \mathrm{NaCl}+0.5 \mathrm{M} \mathrm{H}_{2} \mathrm{SO}_{4}$ solutions.

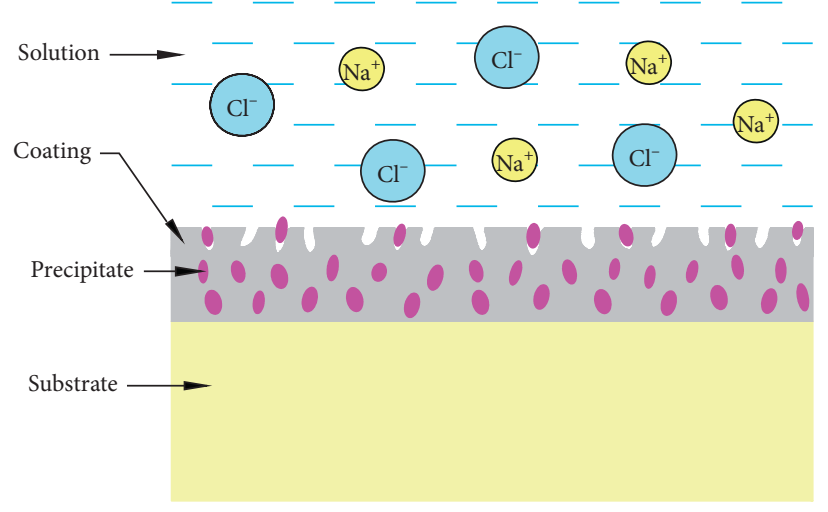

(a)

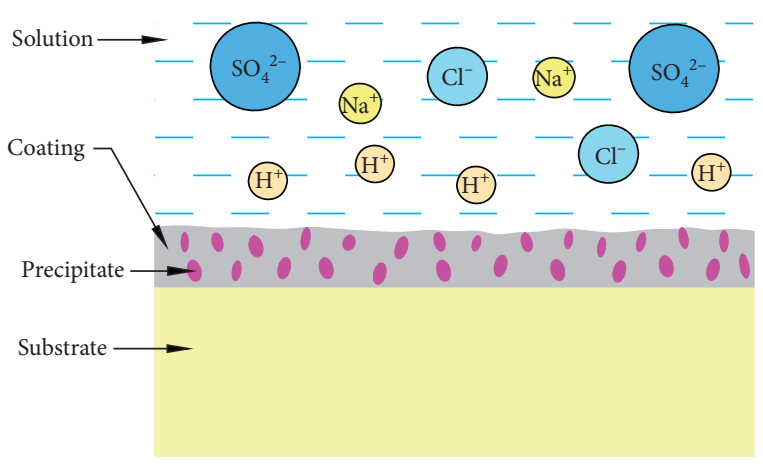

(b)

FIGURE 11: Schematic diagrams of the corrosion mechanisms for laser cladding process prepared Ni45 coatings in (a) $0.5 \mathrm{M} \mathrm{NaCl}$ and (b) $0.5 \mathrm{M} \mathrm{NaCl}+0.5 \mathrm{M} \mathrm{H}_{2} \mathrm{SO}_{4}$ solutions.

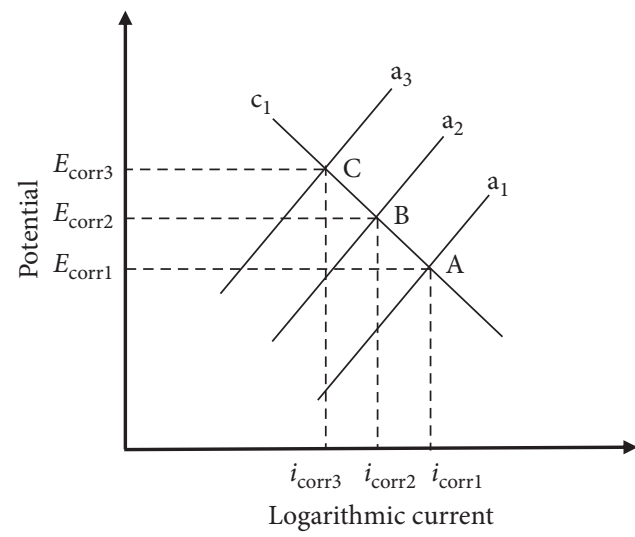

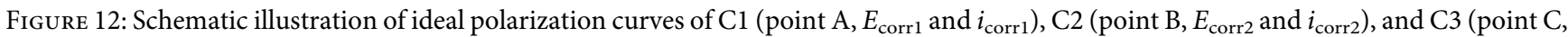
$E_{\text {corr3 }}$ and $i_{\text {corr3 }}$ ) coatings in $0.5 \mathrm{M} \mathrm{NaCl}$ solution. The symbol $\mathrm{cl}$ represents the cathodic polarization curve of all the coatings, and the symbols $\mathrm{a}_{1}, \mathrm{a}_{2}$, and $\mathrm{a}_{3}$ represent the anodic polarization curves of $\mathrm{C} 1, \mathrm{C} 2$, and C3 coatings, respectively. 
reaction rate should differ at various laser scanning speeds. It correlates well with the fact that the difference in anodic curves was more noticeable compared with that in the cathodic curves in $0.5 \mathrm{~mol} / \mathrm{L} \mathrm{NaCl}$ solution as shown in Figure $9(\mathrm{a})$. Therefore, only one oblique line $\left(c_{1}\right)$ is used to represent the unchanged cathodic curve, while three lines $\left(\mathrm{a}_{1}, \mathrm{a}_{2}\right.$, and $\left.\mathrm{a}_{3}\right)$ are used to represent the evolved anodic curves at various laser scanning speeds in Figure 12. The point $A$, the intersection of cathodic curve $c_{1}$ and anodic curve $a_{1}$, is assumed to be the electrochemical corrosion state of $\mathrm{C} 1$ coating (laser scanning speed of $4 \mathrm{~mm} / \mathrm{s}$ ), at which the corrosion potential and corrosion current density are $E_{\text {corr } 1}$ and $i_{\text {corrl }}$, respectively. On increasing the laser scanning speed to $6 \mathrm{~mm} / \mathrm{s}$ (C2 coating) and $10 \mathrm{~mm} / \mathrm{s}$ (C3 coating), less amount of $\mathrm{M}_{23}(\mathrm{C}, \mathrm{B})_{6}$ precipitates formed and the Cr-depleted zones were diminished, consequently leading to inhibited anodic reactions. As a result, the anodic curve will move left along with the axis of current density, from $a_{1}$ to $a_{2}$ and $\mathrm{a}_{3}$, whose intersections are point $\mathrm{B}\left(E_{\mathrm{corr} 2}\right.$ and $\left.i_{\text {corr } 2}\right)$ and point $\mathrm{C} \quad\left(E_{\mathrm{corr} 3}\right.$ and $\left.i_{\text {corr } 3}\right)$, respectively. Evidently, $E_{\text {corr } 1}<E_{\text {corr } 2}<E_{\text {corr } 3}$, while $i_{\text {corr } 1}>i_{\text {corr } 2}>i_{\text {corr3 }}$. The orders for corrosion potential and corrosion current density are identical to those identified in Table 2. Therefore, it should be reasonable to conclude that the improved corrosion resistance of $\mathrm{Ni} 45$ coatings in $0.5 \mathrm{M} \mathrm{NaCl}$ solution is attributed to the inhibited formation of $\mathrm{M}_{23}(\mathrm{C}, \mathrm{B})_{6}$ precipitates at higher laser scanning speeds.

\section{Conclusions}

Ni45 coatings with good interface bonding have been prepared by the laser cladding process. The effects of laser scanning speed $(4 \mathrm{~mm} / \mathrm{s}, 6 \mathrm{~mm} / \mathrm{s}$, and $10 \mathrm{~mm} / \mathrm{s})$ on the microstructure, microhardness, and corrosion resistance of the as-prepared Ni45 coatings are clarified and explained:

(1) The thickness of the transition layer between the coating and HAZ decreased the transformation from planar crystals to dendrites, and the grain refinements in the coatings were promoted. The formation and growth of $\mathrm{M}_{23}(\mathrm{C}, \mathrm{B})_{6}$ precipitates in the coatings were inhibited with increasing laser scanning speed due to lower thermal input and faster cooling rate.

(2) The microhardness of all the coatings presents a downward trend with the increase in laser scanning speed, which is attributed to the weakened precipitation strengthening resulting from the reduced amount of $\mathrm{M}_{23}(\mathrm{C}, \mathrm{B})_{6}$ precipitates. Inside the coating, two distinct layers were identified with different microhardness. The position of the layer with the highest microhardness depended on the laser scanning speed. The competition between precipitation strengthening and grain refinement strengthening accounted for the microhardness distribution in the cross section of the coatings at various laser scanning speeds.

(3) The laser scanning speed exhibited a promotion effect on the corrosion resistance of the as-prepared
$\mathrm{Ni} 45$ coatings in $0.5 \mathrm{M} \mathrm{NaCl}$ solution, whereas no effects could be identified in $0.5 \mathrm{M} \mathrm{NaCl}+0.5 \mathrm{M}$ $\mathrm{H}_{2} \mathrm{SO}_{4}$ solution. The former is ascribed to the inhibited formation of $\mathrm{Cr}$-depleted zones around the $\mathrm{M}_{23}(\mathrm{C}, \mathrm{B})_{6}$ precipitates at higher laser scanning speeds. In contrast, this inhibition effect was invalid in the presence of $0.5 \mathrm{M} \mathrm{H}_{2} \mathrm{SO}_{4}$ because of the highly corrosive feature of the acid solution.

\section{Data Availability}

The data used to support the findings of this study are available from the corresponding author upon request.

\section{Conflicts of Interest}

The authors declare that they have no conflicts of interest.

\section{Acknowledgments}

The authors would like to express their gratitude for the financial support of the National Natural Science Foundation of China (Nos. 51801218, 51911530211, and 51905110) and the Natural Science Foundation of Jiangsu Province (Grant no. BK20191458).

\section{References}

[1] Z. P. Shi, Z. B. Wang, F. G. Chen et al., "Cavitation erosion and corrosion behavior of NiTi cladding with $\mathrm{Cu}$ and $\mathrm{Nb}$ interlayers," Journal of Materials Engineering and Performance, vol. 29, no. 6, pp. 3840-3851, 2020.

[2] Z.-P. Shi, Z.-B. Wang, J.-Q. Wang et al., "Effect of Ni interlayer on cavitation erosion resistance of NiTi cladding by Tungsten Inert Gas (TIG) surfacing process," Acta Metallurgica Sinica, vol. 33, no. 3, pp. 415-424, 2020.

[3] J. L. Chen, J. Li, R. Song, L. L. Bai, J. Z. Shao, and C. C. Qu, "Effect of the scanning speed on microstructural evolution and wear behaviors of laser cladding NiCrBSi composite coatings," Optics \& Laser Technology, vol. 72, pp. 86-99, 2015.

[4] C. T. Kwok, H. C. Man, F. T. Cheng, and K. H. Lo, "Developments in laser-based surface engineering processes: with particular reference to protection against cavitation erosion," Surface and Coatings Technology, vol. 291, pp. 189-204, 2016.

[5] X.-B. Liu, X.-J. Meng, H.-Q. Liu et al., "Development and characterization of laser clad high temperature self-lubricating wear resistant composite coatings on Ti-6Al-4V alloy," Materials \& Design, vol. 55, pp. 404-409, 2014.

[6] Z. Chen, H. Yan, P. Zhang, Z. Yu, Q. Lu, and J. Guo, "Microstructural evolution and wear behaviors of laser-clad Stellite 6/NbC/h-BN self-lubricating coatings," Surface and Coatings Technology, vol. 372, pp. 218-228, 2019.

[7] Z. Zhang and R. Kovacevic, "Laser cladding of iron-based erosion resistant metal matrix composites," Journal of Manufacturing Processes, vol. 38, pp. 63-75, 2019.

[8] X. Li, C. H. Zhang, S. Zhang et al., "Manufacturing of $\mathrm{Ti}_{3} \mathrm{SiC}_{2}$ lubricated Co-based alloy coatings using laser cladding technology," Optics \& Laser Technology, vol. 114, pp. 209-215, 2019.

[9] Q. Wu, W. Li, N. Zhong, W. Gang, and W. Haishan, "Microstructure and wear behavior of laser cladding $\mathrm{VC}-\mathrm{Cr}_{7} \mathrm{C}_{3}$ ceramic coating on steel substrate," Materials \& Design, vol. 49, pp. 10-18, 2013. 
[10] L. Meng, W. Zhao, K. Hou et al., "A comparison of microstructure and mechanical properties of laser cladding and laser-induction hybrid cladding coatings on full-scale rail," Materials Science and Engineering: A, vol. 748, pp. 1-15, 2019.

[11] R. A. R. Rashid, S. Palanisamy, H. Attar, M. Bermingham, and M. S. Dargusch, "Metallurgical features of direct laser-deposited Ti6Al4V with trace boron," Journal of Manufacturing Processes, vol. 35, pp. 651-656, 2018.

[12] G. Telasang, J. Dutta Majumdar, G. Padmanabham, M. Tak, and I. Manna, "Effect of laser parameters on microstructure and hardness of laser clad and tempered AISI H13 tool steel," Surface and Coatings Technology, vol. 258, pp. 1108-1118, 2014.

[13] Y.-h. Cheng, R. Cui, H.-z. Wang, and Z.-t. Han, "Effect of processing parameters of laser on microstructure and properties of cladding 42CrMo steel," The International Journal of Advanced Manufacturing Technology, vol. 96, no. 5-8, pp. 1715-1724, 2018.

[14] M. N. Fesharaki, R. Shoja-Razavi, H. A. Mansouri, and H. Jamali, "Microstructure investigation of Inconel 625 coating obtained by laser cladding and TIG cladding methods," Surface \& Coatings Technology, vol. 353, pp. 25-31, 2018.

[15] D. Tanigawa, N. Abe, M. Tsukamoto et al., "The effect of particle size on the heat affected zone during laser cladding of $\mathrm{Ni}-\mathrm{Cr}-\mathrm{Si}-\mathrm{B}$ alloy on C45 carbon steel," Optics and Lasers in Engineering, vol. 101, pp. 23-27, 2018.

[16] M. B. Henderson, D. Arrell, R. Larsson, M. Heobel, and G. Marchant, "Nickel based superalloy welding practices for industrial gas turbine applications," Science and Technology of Welding and Joining, vol. 9, no. 1, pp. 13-21, 2004.

[17] S. Oukach, B. Pateyron, and L. Pawłowski, "Physical and chemical phenomena occurring between solid ceramics and liquid metals and alloys at laser and plasma composite coatings formation: a review," Surface Science Reports, vol. 74, no. 3, pp. 213-241, 2019.

[18] C. Shi, J. Lei, S. Zhou, X. Dai, and L.-C. Zhang, "Microstructure and mechanical properties of carbon fibers strengthened Ni-based coatings by laser cladding: the effect of carbon fiber contents," Journal of Alloys and Compounds, vol. 744, pp. 146-155, 2018.

[19] S. Sun, H. Fu, X. Ping et al., "Reinforcing behavior and microstructure evolution of $\mathrm{NbC}$ in laser cladded Ni45 coating," Applied Surface Science, vol. 455, pp. 160-170, 2018.

[20] Y. X. Qiao, Z. H. Tian, X. Cai et al., "Cavitation erosion behaviors of a nickel-free high-nitrogen stainless steel," Tribology Letters, vol. 67, no. 1, pp. 1-9, 2019.

[21] K. Zhang, S. Wang, W. Liu, and X. Shang, "Characterization of stainless steel parts by laser metal deposition shaping," Materials \& Design, vol. 55, pp. 104-119, 2014.

[22] X. Jiao, J. Wang, C. Wang, Z. Gong, X. Pang, and S. M. Xiong, "Effect of laser scanning speed on microstructure and wear properties of $\mathrm{T} 15 \mathrm{M}$ cladding coating fabricated by laser cladding technology," Optics and Lasers in Engineering, vol. 110, pp. 163-171, 2018.

[23] X. Zhan, C. Qi, Z. Gao, D. Tian, and Z. Wang, "The influence of heat input on microstructure and porosity during laser cladding of Invar alloy," Optics \& Laser Technology, vol. 113, pp. 453-461, 2019.

[24] P. Tao, H. Li, B. Huang, Q. Hu, S. Gong, and Q. Xu, "The crystal growth, intercellular spacing and microsegregation of selective laser melted Inconel 718 superalloy," Vacuum, vol. 159, pp. 382-390, 2019.

[25] K. Wang, D. Du, G. Liu, Z. Pu, B. Chang, and J. Ju, "Microstructure and mechanical properties of high chromium nickel-based superalloy fabricated by laser metal deposition," Materials Science and Engineering: A, vol. 780, Article ID 139185, 2020.

[26] Y. X. Qiao, X. Cai, C. Ouyang, and Y. G. Zheng, "Effect of hydrogen on cavitation erosion behaviour of high strength steel," International Journal of Electrochemical Science, vol. 11, no. 12, pp. 10329-10346, 2016.

[27] Z. Lei, N. Lu, and X. Yu, "Epitaxy and new stray grain formation mechanism during epitaxial laser melting deposition of Inconel 718 on directionally solidified nickel-based superalloys," Journal of Manufacturing Processes, vol. 42, pp. 11-19, 2019.

[28] X. He, R. G. Song, and D. J. Kong, "Microstructures and properties of $\mathrm{Ni} / \mathrm{TiC} / \mathrm{La}_{2} \mathrm{O}_{3}$ reinforced $\mathrm{Al}$ based composite coatings by laser cladding," Optics \& Laser Technology, vol. 117, pp. 18-27, 2019.

[29] W. Gao, C. Chang, G. Li et al., "Study on the laser cladding of FeCrNi coating," Optik, vol. 178, pp. 950-957, 2019.

[30] D. Kesavan and M. Kamaraj, "The microstructure and high temperature wear performance of a nickel base hardfaced coating," Surface and Coatings Technology, vol. 204, no. 24, pp. 4034-4043, 2010.

[31] H. Liu, P. Chen, H. Yang et al., "Processing window and microstructure of NiCoCrAlY coating deposited on cast iron using multilayer laser cladding," Journal of Spectroscopy, vol. 2019, Article ID 9308294, 15 pages, 2019.

[32] Y. Yang, J. B. Zhan, Z. Z. Sun et al., "Evolution of functional properties realized by increasing laser scanning speed for the selective laser melting fabricated NiTi alloy," Journal of Alloys and Compounds, vol. 804, pp. 220-229, 2019.

[33] G. Q. Liu, X. L. Zhang, X. Y. Wang, and Y. X. Qiao, "Precipitation behavior of the topologically close-packed phase in the DD5 superalloy during long-term aging," Scanning, vol. 2020, Article ID 2569837, 6 pages, 2020.

[34] H. Chen and D. Kong, "Effects of laser remelting speeds on microstructure, immersion corrosion, and electrochemical corrosion of arc-sprayed amorphous Al-Ti-Ni coatings," Journal of Alloys and Compounds, vol. 771, pp. 584-594, 2019.

[35] M. Tavoosi and A. Barahimi, "Corrosion behavior of amorphous-nanocrystalline $\mathrm{Fe}-\mathrm{Ni}-\mathrm{Cr}$ electrodeposited coatings," Surfaces and Interfaces, vol. 8, pp. 103-111, 2017.

[36] H. Shi, Y. X. Qiao, X. Cai et al., "Corrosion behavior of highnitrogen stainless steel in $\mathrm{NaCl}$ solution," International Journal of Electrochemical Science, vol. 12, no. 12, pp. 11298-11308, 2017.

[37] Q. N. Song, N. Xu, W. Gu et al., "Investigation on the corrosion and cavitation erosion behaviors of the cast and friction stir processed $\mathrm{Ni}-\mathrm{Al}$ bronze in sulfide-containing chloride solution," International Journal of Electrochemical Science, vol. 12, no. 11, pp. 10616-10632, 2017.

[38] Y. Qiao, J. Chen, H. Zhou et al., "Effect of solution treatment on cavitation erosion behavior of high-nitrogen austenitic stainless steel," Wear, vol. 424-425, pp. 70-77, 2019.

[39] S. Sinhmar and D. K. Dwivedi, "Effect of weld thermal cycle on metallurgical and corrosion behavior of friction stir weld joint of AA2014 aluminium alloy," Journal of Manufacturing Processes, vol. 37, pp. 305-320, 2019.

[40] Y. X. Qiao, D. K. Xu, S. Wang et al., "Effect of hydrogen charging on microstructural evolution and corrosion behavior of Ti-4Al-2V-1Mo-1Fe alloy," Journal of Materials Science \& Technology, vol. 60, pp. 168-176, 2021.

[41] E. Bettini, T. Eriksson, M. Boström, C. Leygraf, and J. Pan, "Influence of metal carbides on dissolution behavior of 
biomedical CoCrMo alloy: SEM, TEM and AFM studies," Electrochimica Acta, vol. 56, no. 25, pp. 9413-9419, 2011.

[42] Y. Yin, R. G. Faulkner, P. Moreton, I. Armson, and P. Coyle, "Grain boundary chromium depletion in austenitic alloys," Journal of Materials Science, vol. 45, no. 21, pp. 5872-5882, 2010.

[43] H.-J. Kim, S.-H. Jeon, S.-T. Kim et al., "Investigation of the sensitization and intergranular corrosion of tube-to-tubesheet welds of hyper duplex stainless steel using an electrochemical reactivation method," Corrosion Science, vol. 87, pp. 60-70, 2014.

[44] Y. X. Qiao, X. Cai, J. Cui, and H. B. Li, "Passivity and semiconducting behavior of a high nitrogen stainless steel in acidic $\mathrm{NaCl}$ solution," Advances in Materials Science and Engineering, vol. 2016, Article ID 6065481, 9 pages, 2016.

[45] Y. Zheng, S. Luo, and W. Ke, "Effect of passivity on electrochemical corrosion behavior of alloys during cavitation in aqueous solutions," Wear, vol. 262, no. 11-12, pp. 1308-1314, 2007. 